\title{
USE OF MOBILE NETWORKS FOR THE PURPOSE OF PROTECTING PERSONS AND PROPERTY \\ Martin Boroš $^{1}$, Matej Kučera ${ }^{2}$, Ladislav Mariš ${ }^{3}$
}

\begin{abstract}
Mobile networks have been around us for decades, and life without them is difficult to reconstruct. Their gradual evolution has varied over time, depending on the requirements of their users. Originally, they were used only for the transmission of telephony, but transmission in the speech band today is mainly used for data transmission and telephony is in moderate attenuation. Various types of data can be transmitted via mobile networks due to their size or importance.

In the area of security, mobile networks are used from two basic points of view. The first aspect is the use for communication between the components of the electrical security system and the second is the transmission of information from the monitored object to the monitoring and alarm receiving center.

The aim of the paper will be to point out the composition of mobile networks focusing on the functioning of cellular systems and the course of communication between individual parts of the system. The main view will be to the base station of the system without which the functionality of the system would not be possible. In addition to the principle of functionality, we will also focus on utilizing the possibilities of information transmission via mobile networks in terms of property protection and we will focus on the possibility of their use in the future.
\end{abstract}

UDC Classification: 004.7, DOI: 10.12955/cbup.v7.1472

Keywords: base transceiver station, mobile networks, cellular system, communication, transmission system, alarm system.

\section{Introduction}

Information surrounds us and affects us all the time. They differ or influence us directly, or they are only informative to us. Information can be understood as a message that expresses a certain state, serves a purpose and generates a response. We can say that this is an indication, value, fact or other kind of communication that removes uncertainty or ignorance (Štofko el al., 2016).

Information that is communicated via a data set is a function of the data (D), its structure (S), and the time interval $(\mathrm{t})$ in which the communication is in progress. Mathematically, we could write this relationship as follows:

$I=f(D, S, t)$

For each piece of information, it is possible to define two basic pages, which are:

1) Quantitative - which expresses the composition of the message from the individual characters that allow the transmission of the message. This site is important from the point of view of automated information processing,

2) Qualitative - which expresses the adequacy of the factual representation given by the information and usefulness information for the recipient.

The value of the information can be determined by the profit that can be achieved by using it in system activities. It is expressed in a mathematical relation, as follows:

$H=\log \frac{p 2}{p 1}$

Where the parameter $\mathrm{H}$ represents the information value, parameter $\mathrm{p} 1$ represents the likelihood of gaining profit before receiving the information, and parameter $\mathrm{p} 2$ represents the probability of gaining profit after receiving the information.

To facilitate the quantification of information value, we can identify eight basic information attributes which are: availability, completeness, accuracy, relevance, timing, unambiguous, flexibility, and impartiality (Kittel and Loveček, 2011).

\section{Telecommunications networks}

Transmitted information in telecommunications networks are called signals and are transmitted over the necessary distance by electromagnetic waves. For the transmission of this wave, transmission paths are

\footnotetext{
${ }^{1}$ University of Zilina, Faculty of security engineering, Department of Security management, Slovakia, martin.boros@fbi.uniza.sk.

${ }^{2}$ University of Zilina, Faculty of electrical engineering and information technology, Department of Measurement and Applied Electrical Engineering, Slovakia, Matej.kucera @ fel.uniza.sk.

${ }^{3}$ University of Zilina, Faculty of security engineering, Department of Security management, Slovakia, ladislav.maris@fbi.uniza.sk
} 
created by means of, for example, metallic lines, optical lines or free space. In practice, these transmission paths are complementary and combined. The transmission path is based on the distance and volume of information transmitted, and at present the aspect of limiting self-radiation and immunity to electromagnetic compatibility interference is at the forefront. The importance of metallic transmission paths is decreasing and at the same time the use of optical transmission paths is increasing. In the past, radio transmission routes have been of great importance from a safety point of view, the use of which is gradually decreasing (Šebök et al., 2011).

Telecommunications networks are divided by:

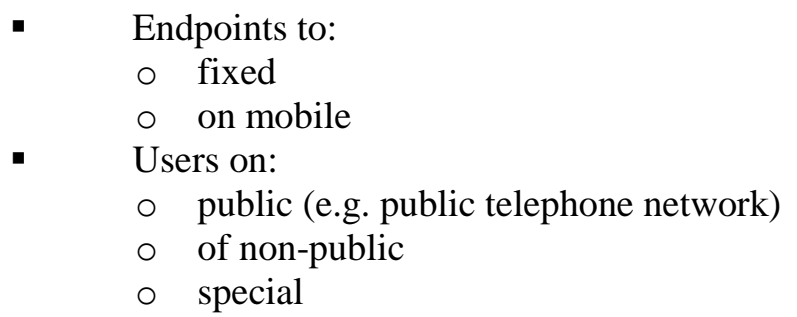

The non-cellular radio communication system in the service area is provided by a powerful transmitter at the highest point of the area, which radiates the radio signal to the radio horizon (approx. $80 \mathrm{~km}$ ). Such a solution results in a relatively good signal coverage of the area, but at the same time it means that a small number of radio channels are blocked on a large area by a small number of calls.

The cellular system solves the problem of area coverage by dividing the area into smaller parts - cells that are serviced by low power transmitters. The basic benefit of the cellular network consists in reducing the area of areas served by certain radio channels. The basic principles of cellular radio networks are low-power transmitters that cover small area signals, reuse of radio channels, cell division and cell sect oration to increase network capacity, call switching during cell border crossing, and centralized system management (Valek et al., 2016).

\section{Base station}

The basis of the cellular systems is the so-called base transceiver station (BTS). BTSs thus represent an essential element of the terrestrial cellular network. It is a radio device with an antenna system, controlled by a Base Station Controller (BSC). They allow the mobile station to physically connect to a network subsystem that includes a Mobile Switching Center (MSC). It is a base station of the GSM network. It is a transmitter and at the same time a receiver that covers a certain area with its signal, a network cell (Rouse, 2007).

Although the beech system has several advantages and covers a relatively large area, there are also areas where, despite symmetrical cell distribution, coverage is not ideal. These are mainly urban areas with uneven development and hilly terrain. In an area with poor coverage, cell densification, increased performance of some cells, or the possibility of directing the signal using special so-called sector antennas are used as compensation. Several directional antennas are mounted around the BTS to ensure even coverage. Each antenna transmits to a different sector, allowing more cells to be served. The antenna operates several frequencies at the same time and each frequency can contain eight voice channels (Vel'as et al., 2017).

In case there are few service customers around the cell, the base stations can only be equipped with an "omnidirectional" antenna. The electromagnetic field is almost uniform around them in all directions.

However, especially in cities, most base stations serve a much larger number of customers. That's why a system of omnidirectional antennas is used. With this technology, antennas achieve significantly higher transmit power in the same space and in the same license class. The most commonly used version is one with three sector antennas. It is a triangular installation in which each antenna covers an area horizontally at $120^{\circ}$. However, the sector antenna does not have the same efficiency in each direction, the efficiency of the radiated power is given by its radiation pattern. For most sector antennas, a vertical beam angle of $5^{\circ}-10^{\circ}$ is most effective. The vertical angle can be adjusted electrically in the range of $2^{\circ}-14^{\circ}$. These parameters cause the front lobe to have the highest radiation efficiency and the radiation is significantly suppressed behind or below the antenna. Sector antennas have a relatively high gain of 15-20 dB (Boroš et al., 2018; Loveček et al., 2017). 


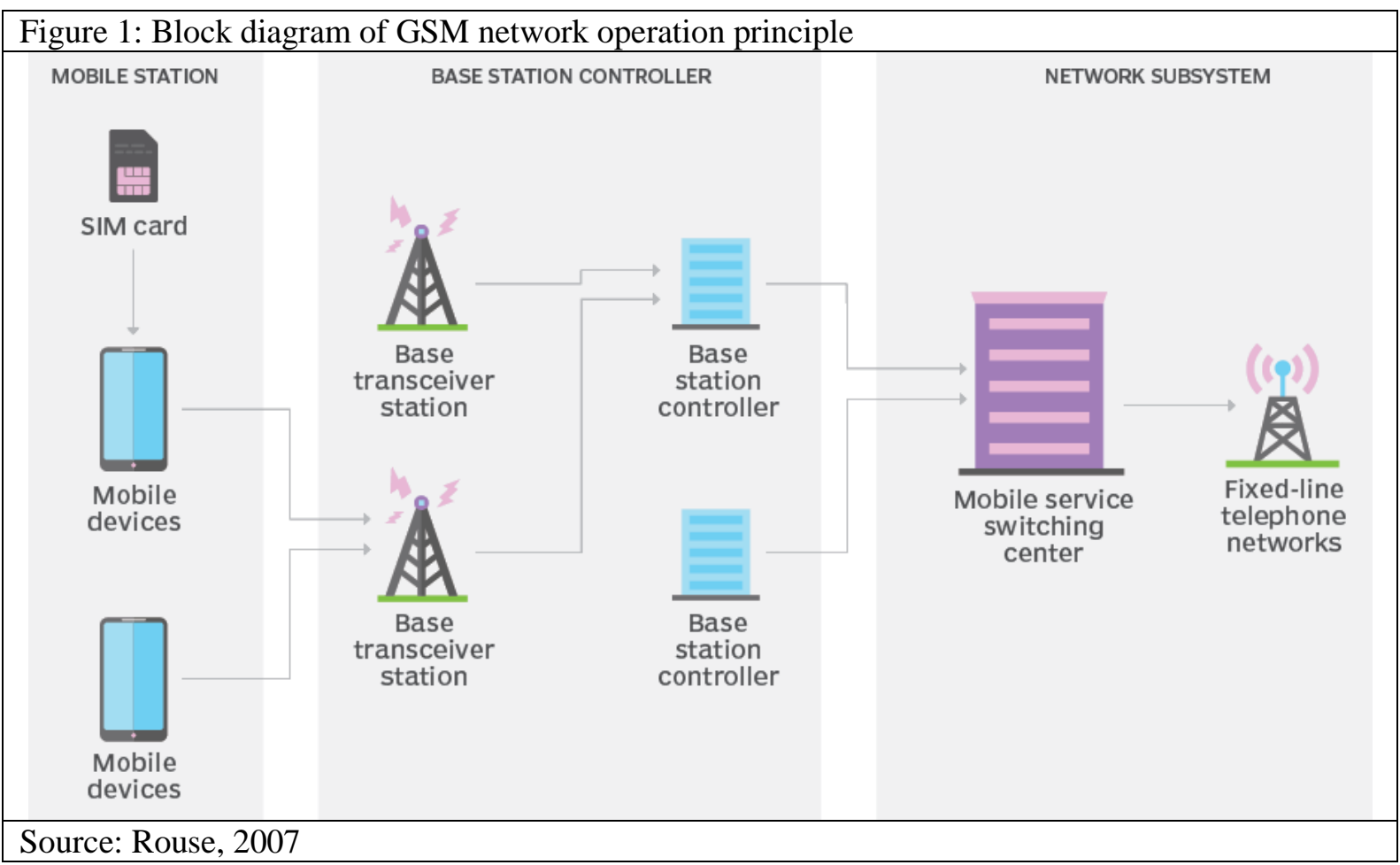

\section{Principle of communication}

All subscriber data is stored in the home subscriber register, which includes information on available services, IMSI numbers and subscriber location information. The IMSI number represents the number assigned by the mobile operator for the SIM card in the mobile GSM network. Each mobile point includes a visitor register that contains information about subscribers moving in the area managed by the base station. These data are stored in the register temporarily and are deleted by the visitor. The Authentication Center verifies the identity of the subscriber in its own databases before commencing communication (Vel'as et al., 2017; Rouse, 2007).

The mobile device register contains mobile station data in the form of an IMEI. An IMEI number is a unique number entered in a mobile phone used to identify the phone in mobile carrier networks. Data transfer between the base station and the mobile device always takes place in two directions. Downlink indicates the signal path from the base station to the mobile device. The uplink is the opposite of the downlink, indicating the route of the signal transmitted by the mobile device to the base station (Kittel and Loveček, 2011; Loveček et al., 2016).

Frequency Division Duplex is a method whereby the base station and the mobile device can simultaneously transmit and receive signals to each other on two different carrier frequencies. In the Time Division Duplex method, the base station and the mobile device use the same carrier frequency for communication with each other, and the roads are separated by a fixed time schedule (Pospíšilík et al., 2017).

\section{Use in security}

There are several uses of GSM networks in security, one of which may be, for example, localization of a mobile station via BTS in case of crisis situations. Each cell of the system has its own Cell ID, and the operator can instantly locate the BTS connection area. In areas with low population density, cells cover an area of up to several kilometers, it is necessary to use additional information to specify the location of the mobile station. For this, Timing advance with TA is used to represent the signal propagation time between the station and the BTS. However, since the TA parameter changes approximately every $550 \mathrm{~m}$ from the BTS, this parameter provides only a rough estimate of the location of the mobile station for low value areas. Localization by triangulation of multiple BTSs supplemented by TA values is the most accurate method. However, this method is technically quite demanding for synchronized BTS communication (Svetlík and Vel'as, 2016; Vocality). 
Another possibility is the transmission of information between the protected object and the monitoring center, to which information about objects is transmitted by means of transmission paths. While in the past mainly radio networks were used for such information transmission, there is now a trend of switching to GSM transmission. This trend is conditioned by the generational exchange of workers as well as the transformation of the job for the security manager. One of the many reasons is also the transfer of responsibility for the management of the transmission site to the mobile operator. Another reason is undoubtedly also the reliability of the GSM transmission site and the speed of information transmission therein (Apeksha Telecom services Pvt Ltd).

In order to transmit a signal in the form of information from a protected object, a GSM communicator must be placed therein by means of which the information about the state of the object is transmitted. In order to send an alarm from a protected object, an alarm system must be installed. An electrical security system is most commonly used as an alarm system which if it detected a violation, the alarm then transmits a signal by a GSM communicator. In addition to the primary function, which is the transmission of intrusion information, it is possible to use a connection to control programmable system outputs. These outputs are most commonly connected to heating control systems, electric blinds, pool heating and the like (Štofko et al., 2016; Loveček et al., 2016).

Other options include using the mobile phone as an external system keypad or entering system instructions via SMS. Thanks to the GSM communicator, it is possible to monitor the mentioned change of environment such as humidity in integrated sensors and then control the value of heating and humidity devices via SMS or by calling the relay (Boroš, 2018).

The GSM network is set as the main alarm transmission path for the transmission of information from protected objects. They are most often used in securing family houses and flats as the only alarm transmission route. In many cases, the potential of the network is exploited, using the GPRS connection as the primary route and the SMS as the backup route. This is based on the potential of the GSM network whose frequency range is very large.

Electronic security systems guard against theft of the building, i.e. windows and doors, logically the interior of the apartment and increasingly the outside space around the house. They are mainly used to detect door and window opening, window glass breakage and various types of motion sensors, which are most probably connected to the alarm. In addition, they can monitor and report fire, flooding, tilt, shocks and movement, including perimeter or tread systems (Kutaj and Boroš, 2017).

Today, detectors can send photos or video of guarded space. The most common are motion detectors or infrared barriers designed for outdoor environment. These are complemented by fire alarms as standard. Gas leakage detectors are installed in buildings where gas appliances are used. It is also possible to monitor the set temperature in the room and so on. Of course, the owner is informed by SMS and voice messages (Technopedia).

LTE networks are increasingly being used not only for commercial use. In the area of security, these are mainly separate networks intended for critical communication in places where there is no GSM network. This principle is mainly used by soldiers in international missions. From a commercial point of view, LTE networks are simulating a smart city (Vocality).

What 4G LTE's predecessors lacked is the critical communication features offered by professional PMR communication systems defined by TETRA or DMR standards. The 3GPP version introduced the concept of critical features within the LTE standard to provide a response to PMR user requests. Near communication services are very important, which allow LTE devices to detect and communicate with each other in the direct mode without infrastructure.

A key limitation on the use of LTE for critical communication is the availability of spectrum for end users. Technologies are moving forward fast. Users require large volumes of data and streaming information. However, there are still some limitations, regarding meeting the immediate and reliable communication requirements for crisis management. Hybrid networks and technologies combining modern LTE networks and traditional digital narrowband technologies can be the solution (Vocality).

Figure 2 shows a block diagram of the use of modern LTE networks in emergency services, which could become part of police equipment across Europe. A similar system is currently being tested at the Faculty of Security Engineering in cooperation with the Municipal Police in Rajec. The aim of this testing is to 
focus on the effective use of modern technologies in the field of security and to point out the possibilities of using GSM networks, other than just for making calls or transferring data between subscribers.

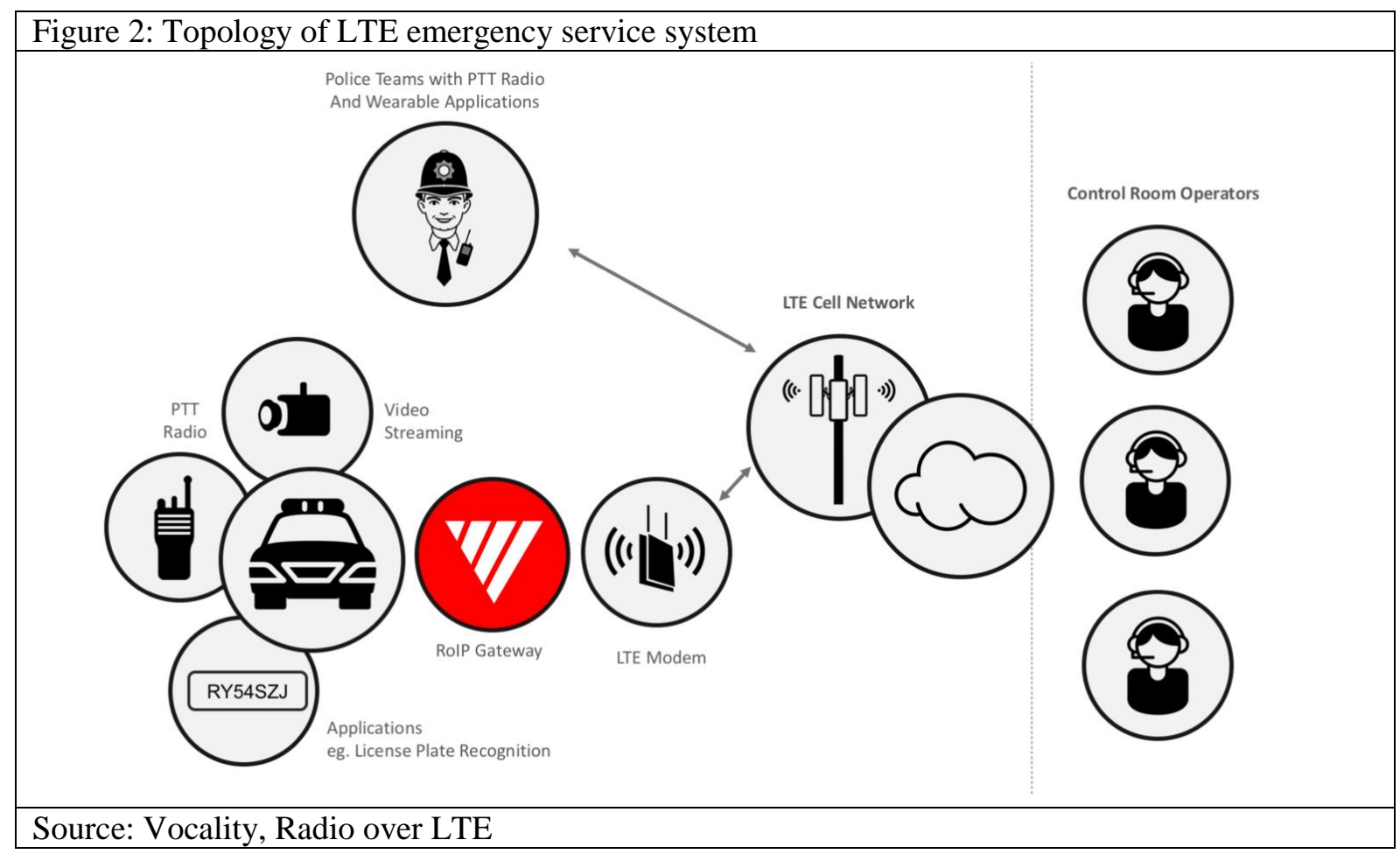

\section{Conclusion}

The aim of this paper was to point out the possibility of using mobile networks in the area of protection of persons and property with a focus on new possibilities. At the beginning of the paper we focused on explaining the principle of mobile networks and at the same time we defined some important terms.

Subsequently, we focused on the possibilities of using mobile networks in terms of protecting people and property in order to focus on security applications that have become part of the lives of many of us. The use of mobile networks in the area of security is a very wide-ranging issue, which highlights the possibilities for their further use. At present, their use is predominantly for making telephone calls or for transmitting data between subscribers. Mobile operators try to increase the transmission rate by which information is transmitted over the network, leaving some frequency bands free or less used.

Network topologies have been created to enable the connection of multiple terminal devices operating within a single system. For example, if an intruder is detected via a video surveillance system, the live stream information is immediately sent to the police officer in charge. This will provide information about the surrounding environment and be better prepared during the transfer to the site. Such a system and its effectiveness in terms of application is tested at the University of Zilina, but as long-term testing of the system is in progress, it is premature to draw conclusions of the experimental deployment of the system in real operation.

\section{Acknowledgment}

This work was supported by the Internal Grant Scheme of Faculty of Security Engineering, University of Zilina from the grant no. IGP 201813 Experimental testing of the reliability of the alarm transmission system and VEGA 1/0768/19 Research on impacts of the socioeconomic development of the region on the citizens security.

\section{References}

Apeksha Telecom services Pvt Ltd. GSM Basic Principles. Online: https://www.apekshatelecom.com/training/telecomtraining/gsm-training/gsm-basic-principles

Boroš, M., The Possibilities of Encryption Information, In: Košická bezpečnostná revue, 2018, ISSN 1338-4880. - Vol. 8, No. 2, p. 1-7. 
Boroš, M., Halaj, M., Vel'as, A., Possibility of Transmitting Alarm Messager Over the Radio Network to the Monitoring and Alarm Receiving Centre, In: CBU International Conference Proceedings 2018, Praha: CBU Research Institute, 2018. ISBN 978-80-270-5037-6. p. 1013-1016. DOI: http://dx.doi.org/10.12955/cbup.v6.1287

Boroš, M., Kutaj, M., Mariš, L., Vel'as, A., Development of Security at the Local Level Through Practical Students Training, In: INTED 2018, 12th International Technology, Education and Development Conference, Valencia, ISBN 978-84-6979480-7. p. 725-729

Kittel, L., Loveček, T., 2011. Passive Protection Elements Breach Resistance Modeling, in Communications: scientific letters of the University of Žilina. Vol. 13, No. 2, p. 53-58

Kučera, M., Šebök, M., 2016. Electromagnetic Compatibility Analysis of Electrical Equipment, in Diagnostic of electrical machines and insulating systems in electrical engineering. Poprad, p. 104-109.

Kučera, M., Šebök, M., 2012. Electromagnetic Compatibility Analysis of Electric Equipments, in Przegląd elektrotechniczny. No 9A, p. 296-299.

Kutaj, M., Boroš, M., Development of a New Generation of Magnetic Contact Based on Hall-effect Sensor, In: CBU International Conference Proceedings 2017, Praha: CBU Research Institute, 2017. ISBN 978-80-88042-07-5. p. 1154-1158. DOI: https://doi.org/10.12955/cbup.v5.1087

Loveček, T., Ristvej, J., Sventeková, E., et al. 2016. Currently Required Competencies of Crisis and Security Managers and New Tool for Their Acquirement. In: 3rd international conference on management innovation and business innovation. Volume: 58. p. 3-8

Loveček, T., Ristvej, J., Sventeková, E., Šiser, A. and Vel'as, A., 2016. Research of Competencies of Crisis and Security Managers, in: 3rd International Conference on Economic, Business Management and Educational Innovation. Singapore Management \& Sports Sci Inst. ISBN 978-981-09-7913-3. p. 172-177.

Loveček, T., Šiser, A., Mariš, L., 2017. Use Case of Waterwork Physical Protection System Robustness Evaluation as a Part of Slovak Critical Infrastructure, in ICCST 2017: 51st international carnahan conference on security technology. Madrid, New York: IEEE.

Rouse, M., 2007. GSM (Global System for Mobile communication), in What is GSM. Online: https://searchmobilecomputing.techtarget.com/definition/GSM

Vel'as, A., Kutaj, M., Durovec, M. Influence of Changing the Parameters of the Camera System on Video-based Motion Detection, In: ICCST 2017: 51st international carnahan conference on security technology: October 23-26, 2017 Madrid, Spain. - New York: IEEE, 2017. - ISBN 978-1-5386-1585-0.

Svetlík, J., Vel'as, A. The Safety Training in the Municipality, In: EDULEARN16: 8th international conference on Education and new learning technologies: Barcelona (Spain), 4th-6th of July 2016: conference proceedings. IATED Academy, 2016. ISBN 978-84-608-8860-4. p. 1350-1355.

Šebök, M., Gutten, M., Kučera, M., 2011. Diagnostics of Electric Equipments by Means of Thermovision, in: Przegląd elektrotechniczny. No. 10, p. 313-317.

Štofko, S., Šoltés, V., Štofková, Z., 2016. Options of Using the Integrated Management System, in Production management and engineering sciences. Leiden: CRC Press, Balkema, p. 267-272.

Technopedia. Global System for Mobile Communications (GSM). Online: https://www.techopedia.com/definition/5062/global-system-for-mobile-communications-gsm

Vocality. Radio Over LTE. Online: https://www.vocality.com/radio-over-lte/ https://www.vocality.com/radio-over-lte/ 